\title{
A novel low-cost detection method for screening of arsenic in groundwater
}

Clàudia Fontàs $^{a^{*}}$, Ruben Vera ${ }^{a}$, Anna Batalla ${ }^{a}$, Spas D. Kolev ${ }^{b}$, Enriqueta Anticó $^{a}$

${ }^{a}$ Department of Chemistry, University of Girona, 17071 Girona, Spain

${ }^{b}$ School of Chemistry, The University of Melbourne, VIC 3010, Australia

\begin{abstract}
In the present work, a novel and simple detection system for As inorganic species contained in groundwater is presented. To reach the required detection limit, the proposed methodology is based on two steps: first the transport and preconcentration of the inorganic arsenic species using a polymer inclusion membrane (PIM) system, and second, the formation of a coloured complex absorbance of which is measured. Different parameters related to the membrane composition and the transport kinetics have been studied and it was found that membranes made of polyvinyl chloride (PVC) as a polymer, and Aliquat 336 as a carrier, ensured efficient arsenic transport when the carrier content was at least $31 \%(\mathrm{w} / \mathrm{w})$. The implementation of the designed PIM in a special device that contained only $5 \mathrm{~mL}$ of the stripping solution $(0.1 \mathrm{M}$ $\mathrm{NaCl}$ ) allowed As preconcentration from a $100 \mathrm{~mL}$ water sample, and, thus, facilitating its detection with the colorimetric method. The new method here developed was validated and its analytical figures of merit were determined, i.e. limit of detection of $4.5 \mu \mathrm{g} \mathrm{L}^{-1}$ at $820 \mathrm{~nm}$ and a relative standard deviation within the range $8-10 \%$. Finally, the method was successfully applied to the analysis of different water samples from Catalonia region with naturally occurring As.
\end{abstract}

Keywords: Arsenic; Polymer Inclusion Membranes; Aliquat 336; Preconcentration; Speciation; groundwater;

*Corresponding author: e-mail: claudia.fontas@udg.edu 


\section{Introduction}

Arsenic is well-known as a potent human carcinogen, and its presence in water, especially groundwater, is a major problem in different areas of the world (Léonard 1991; Villaescusa and Bollinger 2008). Arsenic in the environment is released as inorganic species which can be transformed to organic compounds due to biological activity. Organic As is considered to be less toxic than inorganic As, and in the case of inorganic compounds, the toxicity decreases in the order $\operatorname{arsine}>\mathrm{As}(\mathrm{III})>\mathrm{As}(\mathrm{V})$.. The rate of transformation from one species to the other depends on many factors, like $\mathrm{pH}$, redox potential, and the presence of microorganisms or other oxidizing agents, among others. Under oxidizing conditions As exists as $\mathrm{As}(\mathrm{V})$ compounds, whereas under mildly reducing conditions, it is generally present as As(III) compounds. They both can form different oxyanion species depending on $\mathrm{pH}$.

In the current context of water scarcity, or in developing countries where access to treated water is limited, groundwater that in certain cases may contain high concentrations of arsenic is viewed as a source of drinking water. Globally, over 130 million people are now estimated to be potentially exposed to arsenic in drinking water at concentrations above the World Health Organization (WHO) guideline value of $10 \mu \mathrm{g} \mathrm{L}^{-1}$ (Smedley and Kinniburgh 2002).

To avoid arsenic poisoning, it is of paramount importance to do routine analysis. Arsenic can be measured either in laboratories or in-situ by commercial kits. Analytical laboratory based techniques usually used for As measurements are Hydride Generation Atomic Absorption Spectroscopy (HGAAS), Inductively Coupled Plasma-Atomic Emission Spectrometry (ICP-AES) and Inductively Coupled Plasma-Mass Spectrometry (ICP-MS). These techniques provide sensitivity enough to directly detect arsenic in the water sample at $\mu \mathrm{g} \mathrm{L}^{-1}$ levels. However, they are expensive to run and require equipped laboratories as well as trained staff. To perform in-situ arsenic screening, several kits are commercially available which are economical and simple to use (Arora et al. 2009). Most of the commercial kits are based on Gutzeit method (Kinniburgh and Kosmus 2002). It is based on the transformation of the whole arsenic present in the water sample to arsine by acidifying the sample and adding zinc dust. Then, arsine reacts with mercury bromide impregnated in a paper strip forming a compound with colour varying from yellow to brown depending on the arsine amount generated. It should be noted that the presence of antimony in the sample, as well as the 
presence of hydrogen sulphide, may interfere with this method. In addition the method uses toxic mercury bromide and can produce false negative results due to arsine loss.

Other field tests for arsenic detection are based on anode stripping voltammetry (ASV) (Forsberg et al. 1975). These kits include microelectrodes to carry out the measurement. First, arsenic is collected on the working electrode and then it is oxidized and measured.

As an alternative to the methods employing expensive instrumentation and the in-situ kits using harmful reagents, we have explored the possibility to perform a simple colorimetric As detection after a preconcentration step. For that, we have adopted the well-established molybdenum-blue colorimetric method adapted by Johnson and Pilson (1972) which was originally developed to detect phosphate in waters. It is based on the reaction between $\operatorname{As}(\mathrm{V})$ and ammonium molybdate forming an arsenatomolybdate compound which is colourless. After adding a reducing agent to reduce As(V) to As(III) the intensely blue coloured arsenomolybdenum blue is formed. Since Johnson and Pilson first described in 1972 the experimental conditions for $\mathrm{As}(\mathrm{V})$ determination in the presence of phosphate, several improvements have been reported (Dhar et al. 2004; Lenoble et al. 2003; Tsang et al. 2007). Tsang et al. (2007) used this colorimetric method to directly detect As at around $1 \mu \mathrm{g} \mathrm{L} \mathrm{L}^{-1}$ levels using a custom made dual-beam photometer with a $4 \mathrm{~cm}$ optical path cell and measuring at $\lambda_{\max }=880 \mathrm{~nm}$. However, if we consider the use of a simple spectrophotometer or even better, the possibility of a detection of the colour by the naked eye (which would simplify even more the system), arsenic concentrations must be higher than the typical As content in waters. Thus, a preconcentration step is essential to reach the required concentration of As to allow its colorimetric detection.

In this study, we have investigated the use of a device containing a functionalized membrane to transport As from the water sample to a smaller volume of the corresponding stripping solution. Taking advantage of the differences in the volumes, As will be enriched and its colorimetric detection will be possible. Previous results obtained by us have demonstrated that functionalized membranes can be used to extract and transport arsenate species from natural waters. The transport mechanism is based on the fact that inorganic anionic species of $\mathrm{As}(\mathrm{V})$ present in waters at neutral $\mathrm{pH}$ (mainly $\mathrm{H}_{2} \mathrm{AsO}_{4}{ }^{-}$and $\mathrm{HAsO}_{4}{ }^{2-}$ ) can be extracted by anion-exchangers carriers, such as Aliquat 336, included in both a supported liquid membrane (SLM) (Güell et al. 2010) and a polymer inclusion membrane (PIM) (Güell 
et al. 2011a). Besides, commercial ion exchange membranes (IEM) containing anionexchange groups were also found to be suitable for the transport of arsenate (Güell et al. 2011b). For all type of membranes mentioned above, a solution of $0.1 \mathrm{M} \mathrm{NaCl}$ ensured a quantitative transport of the extracted species due the concentration gradient of $\mathrm{NaCl}$.

Under neutral $\mathrm{pH}$ conditions inorganic $\mathrm{As}(\mathrm{III})$ transport was negligible since it is mainly present as a neutral species $\left(\mathrm{H}_{3} \mathrm{AsO}_{3}\right)$ (Güell et al. 2010; Güell et al. 2011a; Güell et al. 2011b). This different behaviour of $\mathrm{As}(\mathrm{V})$ and $\mathrm{As}(\mathrm{III})$ inorganic species when contacted with membranes incorporating an anion-exchanger is the basis of As speciation.

On the basis of the above considerations we decided to use a device containing a PIM since this kind of membranes are more stable than SLMs and more versatile than commercial IEMs. Hence, in the present research we present the different parameters related to the method development, as well as method validation and application to several water samples containing

naturally occurring elevated levels of As (higher than $10 \mu \mathrm{g} \mathrm{L}^{-1}$ ) from the region of Girona (Spain).

\section{Experimental}

\subsection{Reagents and solutions}

Stock solutions (100 $\left.\mathrm{mg} \mathrm{L}^{-1}\right)$ of $\mathrm{As}(\mathrm{V})$ and $\mathrm{As}(\mathrm{III})$ were prepared from the solids $\mathrm{Na}_{2} \mathrm{HAsO}_{4} \cdot 7 \mathrm{H}_{2} \mathrm{O}$ (Merck) and $\mathrm{NaAsO}_{2}$ (Fluka) respectively. Solutions of As(V) in Milli-Q water were prepared by dilution of the corresponding stock solutions and the resulting $\mathrm{pH}$ was 7. However, to establish this $\mathrm{pH}$ in the case of $\mathrm{As}(\mathrm{III})$, it was necessary to add $\mathrm{HCl}$. Sodium chloride (Fluka) was used to prepare the stripping solution. Hydrogen peroxide (Fluka) was employed to oxidize $\mathrm{As}(\mathrm{III})$ to $\mathrm{As}(\mathrm{V})$ according to the procedure adapted from a previous study (Yang et al. 1999). Calibration standards of As were prepared using the Spectrascan standard solution for atomic spectroscopy (Teknolab). All reagents and solvents were of analytical reagent grade and distilled water was purified by a Milli-Q Plus system (Millipore).

The extractantAliquat 336, which is a mixture of quaternary alkylammonium chlorides, and the polymer polyvinyl chloride (PVC) were purchased from Fluka Chemie. A 0.5 M Aliquat 336 solution in tetrahydrofuran (THF) (Panreac, Spain), was used to prepare the polymeric films.

For the molybdenum blue method, the colorimetric reagent solutions were prepared in 
accordance with the latest and improved version of the method of Tsang et al. (Tsang et al. 2007). A solution of ammonium molybdate was prepared by dissolving $5.2 \mathrm{~g}$ of $\left(\mathrm{NH}_{4}\right)_{6} \mathrm{Mo}_{7} \mathrm{O}_{24} \cdot 4 \mathrm{H}_{2} \mathrm{O}$ (Scharlau) and $8.8 \mathrm{mg}$ of potassium antimonyl tartrate, $\mathrm{K}(\mathrm{SbO}) \mathrm{C}_{4} \mathrm{H}_{4} \mathrm{O}_{6} \cdot 0.5 \mathrm{H}_{2} \mathrm{O}$ (Merck), in $30 \mathrm{ml}$ of $9 \mathrm{M}$ sulphuric acid and diluted by deionized water to $50 \mathrm{ml}$ in a volumetric flask. Ascorbic acid is used as a reductant and a solution $10 \%$ (w/v) of ascorbic acid (Panreac) was prepared daily. The reagents were added to As(V) samples or standard solutions according to the recommended procedure (Tsang et al. 2007). To account for the matrix effect, standard solutions were prepared in both Milli-Q water and $0.1 \mathrm{M} \mathrm{NaCl}$.

\subsection{Polymer inclusion membranes preparation}

PIMs were prepared according to the procedure previously described (Güell et al. 2011a). Briefly, $400 \mathrm{mg}$ of PVC were dissolved in $20 \mathrm{~mL}$ THF and adding the appropriate amount of the Aliquat 336 solution in THF. This mixture was poured into a $9.0 \mathrm{~cm}$ diameter flat bottom glass Petri dish which was set horizontally and covered loosely. The solution was allowed to evaporate over 24 hours at room temperature. The resulting film was then carefully peeled off the bottom of the Petri dish and circular pieces with an area of $11.6 \mathrm{~cm}^{2}$ or $2.5 \mathrm{~cm}^{2}$ were cut from its central section and used in the transport or preconcentration experiments, respectively.

\subsection{Transport and preconcentration experiments}

Preliminary experiments to optimize the transport system were performed in a two compartment membrane cell described elsewhere (Güell et al. 2010), where $190 \mathrm{~mL}$ of both feed and stripping solutions $(0.1 \mathrm{M} \mathrm{NaCl})$ were used.

The device designed for preconcentration purposes (PIM-device) consists of a glass tube with two openings, one at the top $(0.9 \mathrm{~cm}$ diameter $)$ and another one at the bottom $(1.8$ $\mathrm{cm}$ diameter). The PIM was placed at the bottom opening and fixed with a screw cap specially designed to expose the maximum membrane area to the sample solution $\left(2.5 \mathrm{~cm}^{2}\right)$. The opening at the top was closed with a standard screw cap and was used to fill the device with the appropriate volume of stripping solution. 
To carry out the experiments using this device, $100 \mathrm{ml}$ of arsenic containing water were poured into a glass beaker placed on a magnetic stirrer. The device incorporating the membrane and stripping solution $(5 \mathrm{~mL} 0.1 \mathrm{M} \mathrm{NaCl})$ was immersed $1 \mathrm{~cm}$ in the sample solution in a vertical position. To better facilitate As transport the water solution was continuously stirred. After a predetermined contact time the device was removed from the solution and a selected volume of the stripping solution (usually 4 or $2 \mathrm{~mL}$ ) was taken for analysis.

Arsenic transport efficiency (TE) was determined by using Eq. (1):

$$
T E(\%)=\frac{[A s]_{\text {strip }_{(t)}}}{[A s]_{\text {feed }_{(0)}}} \frac{1}{V r} \times 100
$$

where $[\mathrm{As}]_{\text {strip }(\mathrm{t})}$ denotes the As concentration in the stripping compartment at the end the contact time, whereas $[\mathrm{As}]_{\mathrm{fed}(0)}$ is the initial As concentration in the water sample. The volume ratio between feed solution and stripping solutions is denoted by $\mathrm{V} r$. For the twocompartment cell $\mathrm{V} r=1$, and for the PIM device $\mathrm{V} r=20$.

As a minimum, duplicate experiments were performed. All experiments were conducted at $22 \pm 1^{\circ} \mathrm{C}$.

\subsection{Apparatus}

An HP- Diode Array instrument was used to measure the absorbance of the arsenic complex at $\lambda=820 \mathrm{~nm}$. Absorbance measurements were carried out for method validation once all the experimental parameters were optimized.

A sequential inductively coupled plasma atomic emission spectrometer (ICP-AES) (Liberty RL, Varian, Mulgrave, Vic., Australia) was used to determine the arsenic concentration in the aqueous stripping solutions. Measurements were conducted at $\lambda=228.812$ $\mathrm{nm}$. Major cations like $\mathrm{Na}, \mathrm{Ca}, \mathrm{Mg}$ and $\mathrm{K}$ were also measured with this instrument.

For arsenic concentrations at the $\mu \mathrm{g} \mathrm{L}^{-1}$ level, a quadrupole-based ICP-MS system (Agilent 7500c, Agilent Technologies, Tokyo, Japan) equipped with an octapole collision reaction cell was employed. The isotope ${ }^{75}$ As was selected and special conditions in the

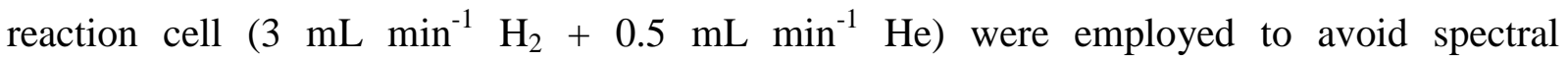
interferences due to the presence of chloride in water samples. 
The anionic composition of the water samples was determined by an ion chromatograph (IC) DIONEX IC5000 equipped with an autosampler AS-AP, a conductivity detector, and a IonPac ${ }^{\circledR}$ AS18 anion-exchange column $(4 \times 250 \mathrm{~mm})$ with the AG Guard column (4x50 mm).

The $\mathrm{pH}$ and conductivity values were determined with a Crison Model GLP $22 \mathrm{pH}$ meter and Ecoscan, Entech Instruments, portable conductimeter, respectively.

\subsection{Water samples}

Water samples containing arsenic naturally occurring and others without arsenic were collected in the north part of Catalonia (Spain). The samples were analysed and their composition is depicted in Table 1. Lles and Setcases are villages located close to the Pyrenees Mountains, and three different wells were sampled in each place. At Caldes the water was collected from a hot spring. Additionally, tap water from Girona city was also collected to study possible anions interferences in the arsenate transport.

\section{Results and discussion}

\subsection{Efficiency of the PIM system for inorganic As transport}

\subsubsection{Composition of the membrane}

Normally PIMs consist of a polymer which provides mechanical strength, a carrier, which is the responsible for the extraction process, and sometimes a plasticizer can be used to provide elasticity or a modifier to vary the membranes properties. In our previous work (Güell et al. 2011a), a PIM made of CTA as the polymer and Aliquat 336 as the carrier exhibited a very good performance in terms of inorganic $\mathrm{As}(\mathrm{V})$ transport. In this study, however, we wanted to explore the use of the polymer PVC for As transport. It has been reported that PIMs made of PVC and Aliquat 336 are very efficient for the transport of different species such as thiourea (Sakai et al. 2000), Cd in chloride media (Xu et al. 2004) or Cr(VI) (Gherasim et al. 2011). Moreover, Pereira et al. (Pereira et al. 2009) have studied the compatibility of this polymer and Aliquat 336, and showed that this combination resulted in successful membranes.

The stability of a PIM made of 60\%(w/w) PVC and 40\%(w/w) Aliquat 336 has also been investigated by Kagaya et al. (Kagaya et al. 2012) who have suggested that though PIMs are 
capable of losing membrane liquid phase, this loss leads to a stable membrane composition with minimal further loss of membrane liquid phase.

From our preliminary study on inorganic As(V) transport using PVC-based PIMs, it was observed that better results were obtained when the PIM did not contain any plasticizer (Fontàs et al. 2012). Thus, in the present work, we investigated PIMs containing only PVC and $20 \%(\mathrm{w} / \mathrm{w})$ or $31 \%(\mathrm{w} / \mathrm{w})$ Aliquat 336 . The transient concentration curves corresponding to these two membrane compositions are depicted in Fig.1. As it can be observed, the PIM with the lower concentration of Aliquat 336 allowed the transport of As but only with a $30 \%$ transport efficiency in 300 min (Fig. 1(a)). However, the PIM containing 10\% more Aliquat 336 (Fig. 1(b)) allowed the quantitative transport of As for the same period of time. Thus, a PIM composition of $69 \%(\mathrm{w} / \mathrm{w})$ PVC and 31\%(w/w) Aliquat 336 was selected for the subsequent experiments.

\subsubsection{Transport of inorganic As(III)}

As stated above, the transport of inorganic As(III) species at neutral $\mathrm{pH}$ is not favourable using anion-exchangers as carriers. Therefore, for total inorganic As (i.e. As(III) and $\mathrm{As}(\mathrm{V})$ ) analysis, a preliminary oxidizing step is required to ensure that all inorganic As species are in the arsenate form. In the literature, different approaches are proposed for oxidizing As(III) to As(V), such as the use of hydrogen peroxide, activated carbon or titanium dioxide (Yang et al. 1999). In the present work, we investigated the photolytic oxidation reaction assisted by hydrogen peroxide as a simple and cost-effective method to allow total As transport. In this method $0.5 \mathrm{~mL}$ of the commercial $\mathrm{H}_{2} \mathrm{O}_{2}$ solution were added to $200 \mathrm{~mL}$ of 10 $\mathrm{mg} \mathrm{L}^{-1} \mathrm{As}(\mathrm{III})$ solution. The solution was exposed to sun light for $40 \mathrm{~min}$ and then $\mathrm{pH}$ was adjusted to 7. The complete oxidation of $\mathrm{As}(\mathrm{III})$ to $\mathrm{As}(\mathrm{V})$ was verified by the molybdenum blue method. After this treatment, the resulting solution was used as a feed solution in the PIM separation system. Fig. 2 shows the transport profiles for inorganic As(III) solutions with and without an oxidizing pretreatment step. This pretreatment step resulted in the quantitative transport of inorganic As(III) as As(V), thus allowing total inorganic As measurement with the proposed PIM system. In the absence of an oxidizing pretreatment step only inorganic As(V) can be measured. Therefore, measurements with and without the pretreatment step will allow the quantification of both arsenate and arsenite in the water samples analysed. 


\subsection{Arsenic preconcentration using the PVC-based device}

To demonstrate that the preconcentration of arsenate was possible using the PIM system, different PIM-devices were contacted with $100 \mathrm{~mL}$ solution of $100 \mu \mathrm{g} \mathrm{L}^{-1}$ inorganic As(V) in Milli-Q water for 24 hours under constant agitation. After this period of time, the arsenic content in the stripping solution was analyzed. Results for 4 different experiments using different membrane pieces from the same original membrane or from different membranes were obtained and it was found that arsenate was effectively concentrated in the stripping phase, with concentrations varying from 1340 to $1530 \mu \mathrm{g} \mathrm{L}^{-1}$. The determination of $\mathrm{As}(\mathrm{V})$ in the stripping phase was then conducted by the colorimetric molybdenum blue method, while direct measurement of $\mathrm{As}(\mathrm{V})$ was not possible in the original $100 \mu \mathrm{g} \mathrm{L}^{-1}$ solution. Under these conditions, we obtained a transport efficiency of 68-76\% calculated by Eq.(1) and a variation coefficient of 5\%. These results led to further investigation of the suitability of the proposed device as an analytical tool for As monitoring.

Moreover, the kinetics of the transport is an important issue to take into account since it will determine the time needed for the whole procedure. Thus, different PIM-devices were mounted (to stop them at the desired time) and were immersed in $100 \mathrm{~mL}$ milli-Q water with $100 \mu \mathrm{g} \mathrm{L}^{-1}$ inorganic As(V). Fig. 3 illustrates the kinetics of the arsenate preconcentration where it can be seen that the maximum transport efficiency was achieved after $17 \mathrm{~h}$ of contact under agitation. However, for practical considerations, we fixed $24 \mathrm{~h}$ for the subsequent experiments.

\subsubsection{Effect of feed composition}

The influence of the feed $\mathrm{pH}$ and matrix composition on the device performance was studied. The effect of feed $\mathrm{pH}$ on arsenate transport was discussed in detail by us in a previous study involving PIMs (Güell et al. 2011a). These membranes exhibited the fastest transport for inorganic $\mathrm{As}(\mathrm{V})$ in the $\mathrm{pH}$ range between 5 and 7. This $\mathrm{pH}$ range overlaps with the $\mathrm{pH}$ range of most natural waters. The same optimal $\mathrm{pH}$ range for the transport of inorganic As(V) was observed for the PVC based PIM used in the present study indicating that there was no need of $\mathrm{pH}$ adjustment of natural waters prior to their inorganic As analysis with the proposed PIM based device. 
Considering that the PIM transport mechanism is based on anionic exchange, it is well known that not only arsenic species but also other anions present in natural water samples can be transported through the membrane, and, thus, these anionic species can potentially interfere with the preconcentration of the target analyte. Natural water may have a very different composition (e.g. Table 1). To evaluate matrix effect we tested arsenic transport for natural waters containing arsenic as well as tap water from Girona spiked with arsenate. The transport efficiencies for these natural waters are compared in Table 2 with that for milli-Q water. Even though the conductivity of the waters studied as well as their initial arsenic concentration was different, similar transport efficiencies were obtained except for the hot spring where no As transport was observed. In the case of spiked tap water sample, we also determined the percentage of other anions transported to the stripping phase. It was found that $75 \%$ of sulphate and $27 \%$ of nitrate were also co-transported along with arsenate. These results indicate that arsenate is preconcentrated, even in the presence of other anionic species, if the total concentration of anions does not exceed the chloride concentration in the stripping solution needed to ensure the chemical pumping. This condition was not fulfilled in the case of the hot spring water from Caldes, where the high chloride content of the sample hampered the efficient transport of arsenate. The conductivity of a water sample can be used as an indicator of the suitability of the membrane system for inorganic As analysis.

\subsection{Analytical figures of merit}

The proposed preconcentration method was applied to standards containing $A s(V)$ in the range 20 to $120 \mu \mathrm{g} \mathrm{L}^{-1}$ in Milli-Q water with the molybdenum blue method used for measuring the concentration of $\mathrm{As}(\mathrm{V})$ in the stripping solution. Fig.4 shows the calibration curves obtained for the analysis of the $\mathrm{As}(\mathrm{V})$ standards by the molybdenum blue method with and without preconcentration using the PIM-device. From the slope of each calibration curve it can be stated that the sensitivity of the method using the PIM-based device is 17 times higher than that of the direct analysis. Possible variations due to matrix effects were examined by constructing calibration curves in the natural water Setcases 1 (see Table 1 for composition). The resulting calibration curves presented very similar parameters (slope value: 0.0053 ( $\mathrm{SD}=0.0002$ ) for milli-Q water and 0.0055 ( $\mathrm{SD}=0.0003$ ) for Setcases 1 water). 
The limit of detection (LOD) was calculated for signal equal to three times the standard deviation of a solution containing $20 \mu \mathrm{g} \mathrm{L}^{-1}$ As $(\mathrm{V})$. An LOD of $4.5 \mu \mathrm{g} \mathrm{L}^{-1}$ was obtained. This value is lower than the regulated value from the WHO.

Inter-day repeatability was evaluated at two concentration levels, $20 \mu \mathrm{g} \mathrm{L}^{-1}(\mathrm{n}=5)$ and $100 \mu \mathrm{g} \mathrm{L}^{-1}$ (n=3). The standard deviation (SD) for these measurements is $2 \mu \mathrm{g} \mathrm{L}^{-1}$ and $8 \mu \mathrm{g} \mathrm{L}^{-}$ ${ }^{1}$, respectively.

\subsection{Application to natural water samples}

The proposed method was used to analyze natural waters from the Pyrenees region containing arsenic. The results obtained are compared with those obtained with ICP-MS in Table 3. The good agreement obtained shows that As in the water samples is present as As(V) and that the developed method is suitable for As detection.

\section{Conclusions}

A simple device for arsenic preconcentration based on the use of a $69 \%(\mathrm{w} / \mathrm{w}) \mathrm{PVC}$ and $31 \%(\mathrm{w} / \mathrm{w})$ Aliquat $336 \mathrm{PIM}$ is proposed where the measurement of the preconcentrated As in the stripping solution is done by the molybdenum-blue colorimetric method. The PIM-device is easy to operate and uses a non-toxic stripping reagent (i.e. sodium chloride solution). An LOD of $4.5 \mu \mathrm{g} \mathrm{L}^{-1}$ was obtained showing that the proposed method is suitable for the determination of arsenic in ground waters to be used as a source of drinking water. The performance of the PIM-device has been evaluated and very good agreement has been achieved between results obtained by the proposed method and by ICP-MS. Moreover, PIMdevice has successfully been used for the analysis of naturally occurring arsenic waters with low conductivity. Considering both the simplicity and the use of non toxic reagents, this new method can be viewed as an attractive alternative to existing methods for As monitoring.

\section{Acknowledgements}

Dena Desarrollos S.A. is acknowledged for the financial support of this research. 


\section{References}

Arora M, Megharaj M, Naidu R (2009) Arsenic testing field kits: some considerations and recommendations. Environ Geochem Health 31:45-48

Dhar RK, Zheng Y, Rubenstone J, Van Geen A (2004) A rapid colorimetric method for measuring arsenic concentrations in groundwater. Anal. Chim. Acta 526:203-209.

Fontàs C, Batalla A, Anticó E, Kolev SD, Illa A (2012) A novel membrane-based approach for the remote screening of As in waters. Proc. Engineer. 44:801-803.

Forsberg G, Olaughlin JW, Megargle R G, Koirtyohann SR (1975) Determination of arsenic by anodic stripping voltammetry and differential pulse anodic stripping voltammetry. Anal Chem 47:1586-1592.

Gherasim C, Bourceanu G, Olariu R, Arsene C (2011) A novel polymer inclusion membrane applied in chromium (VI) separation from aqueous solutions. J. Hazard. Mat. 197:244-253.

Güell R, Fontàs C, Salvadó V, Anticó E (2010) Modelling of liquid-liquid extraction and liquid membrane separation of arsenic species in environmental matrices. Sep Pur Technol 72:319-325.

Güell R, Anticó E, Kolev SD, Benavente J, Salvadó V, Fontàs C (2011a) Development and characterization of polymer inclusion membranes for the separation and speciation of inorganic As species. J Membr Sci 383:88-95.

Güell R, Fontàs C, Anticó E, Salvadó V, Crespo JG, Velizarov S (2011b) Transport and separation of arsenate and arsenite from aqueous media by supported liquid and anionexchange membranes, Sep Pur Technol 80:428-434.

Johnson DL, Pilson MEQ (1972) Spectrophotometric determination of arsenite, arsenate, and phosphate in natural waters. Anal Chim Acta 58:289-299.

Kagaya S, Ryokan Y, Cattrall RW, Kolev SD (2012) Stability studies of poly(vinyl chloride)based polymer inclusion membranes containing Aliquat 336 as carrier. Sep Purif Technol. 101:69-75.

Kinniburgh DG, Kosmus W (2002) Arsenic contamination in groundwater: some analytical considerations. Talanta 58:165-180.

Lenoble V, Deluchat V, Serpaud B, Bollinger JC (2003) Arsenite oxidation and arsenate determination by the molybdenum blue method. Talanta 61:267-276. 
Leónard A (1991) Arsenic. In: Merian E (ed) Metals and their compounds in the environment. Occurrence, analysis and biological relevance. Weinheim: VCH, New York, pp 751-774.

Pereira N, St John A, Cattrall RW, Perera JM, Kolev SD (2009) Influence of the composition of polymer inclusion membranes on their homogeneity and flexibility. Desalination 236:327333.

Sakai Y, Cattrall RW, Paimin R, Potter ID, Kolev SD (2000) Transport of thiourea through an Aliquat 336/PVC membrane. Sep Sci Technol 35:1979-1990.

Smedley PL, Kinniburgh DG (2002) A review of the source, behaviour and distribution of arsenic in natural waters. Applied Geochemistry 17:517-568.

Tsang S, Phu F, Baum MM, Poskrebyshev GA (2007) Determination of phosphate/arsenate by a modified molybdenum blue method and reduction of arsenate by $\mathrm{S}_{2} \mathrm{O}_{4}{ }^{2-}$. Talanta 71:15601568.

Villaescusa I, Bollinger JC (2008) Arsenic in drinking water: sources, occurrence and health effects (a review). Rev Environ Sci Biotechnol 7:307-323.

Xu J, Wang L, Shen W, Paimin R, Wang X (2004) The influence of the interior structure of Aliquat 336/PVC membranes for their extraction behaviour. Sep Sci Technol 39:3527-3539.

Yang H, Lin WT, Rajeshwar K (1999) Homogeneous and heterogeneous reactions involving As(III) and As(V) species in aqueous media. J Photochem. Photobiol, A 123:137-143. 


\section{Figure captions}

Figure 1. Transient concentration curves of inorganic $\mathrm{As}(\mathrm{V})$ transport experiments in a two compartment cell, $\mathrm{Vr}=1$. A PIM made of 80\% PVC-20\% Aliquat 336 (w/w) (a) and 69\% PVC-31\% Aliquat 336 (w/w) (b) were used. Feed solution: $10 \mathrm{mg} \mathrm{L}^{-1}$ inorganic As(V), pH=7; Stripping solution: $0.1 \mathrm{M} \mathrm{NaCl}$.

Figure 2. Transient concentration curves of inorganic As(III) oxidation/transport experiments in a two compartment cell, Vr= 1 (PIM: 69\% PVC-31\% Aliquat 336 (w/w); Feed solution: 10 $\mathrm{mg} \mathrm{L}^{-1}$ inorganic As(III), $\mathrm{pH}=7$; Stripping solution: $0.1 \mathrm{M} \mathrm{NaCl}$.

Figure 3. Kinetics of $\mathrm{As}(\mathrm{V})$ transport using the PIM-device (Vr= 20). PIM: 69\% PVC-31\% Aliquat 336 (w/w); Feed solution: $100 \mathrm{~mL}$ of $100 \mu \mathrm{g} \mathrm{L}^{-1}$ inorganic $\mathrm{As}(\mathrm{V})$ at $\mathrm{pH}=7$; Stripping solution: $5 \mathrm{~mL} 0.1 \mathrm{M} \mathrm{NaCl}$.

Figure 4. Calibration curves obtained with (PIM-device, $\mathrm{Vr}=20$ ) and without the PIM preconcentration step. PIM: 69\% PVC-31\% Aliquat $336(\mathrm{w} / \mathrm{w})$. Feed solution: $100 \mathrm{~mL}$ of different inorganic $\mathrm{As}(\mathrm{V})$ concentrations in milli-Q water at $\mathrm{pH}=7$; Stripping solution: $5 \mathrm{~mL}$ 0.1 M NaCl (SD direct measurement: 0.002 A.U.; SD PIM-device: 0.003 A.U.; n=4 in both cases). 
Figure 1

(a)

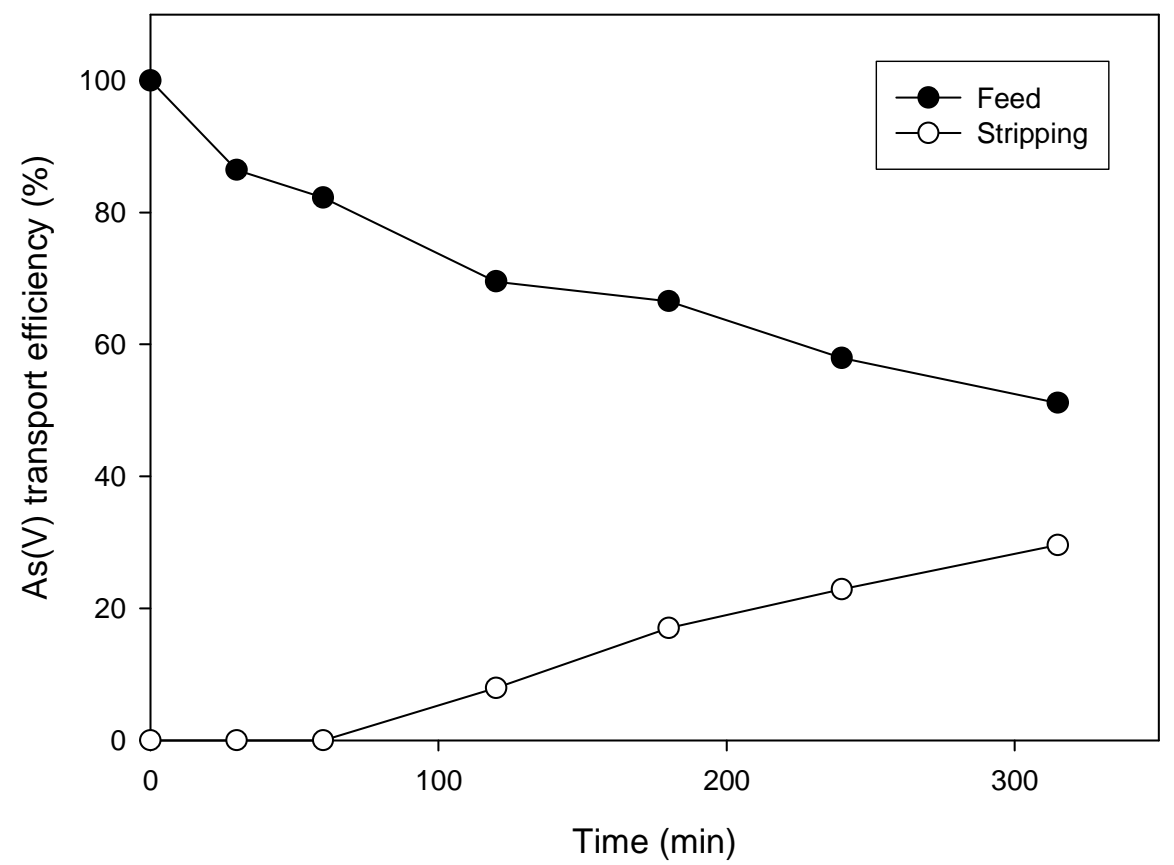

(b)

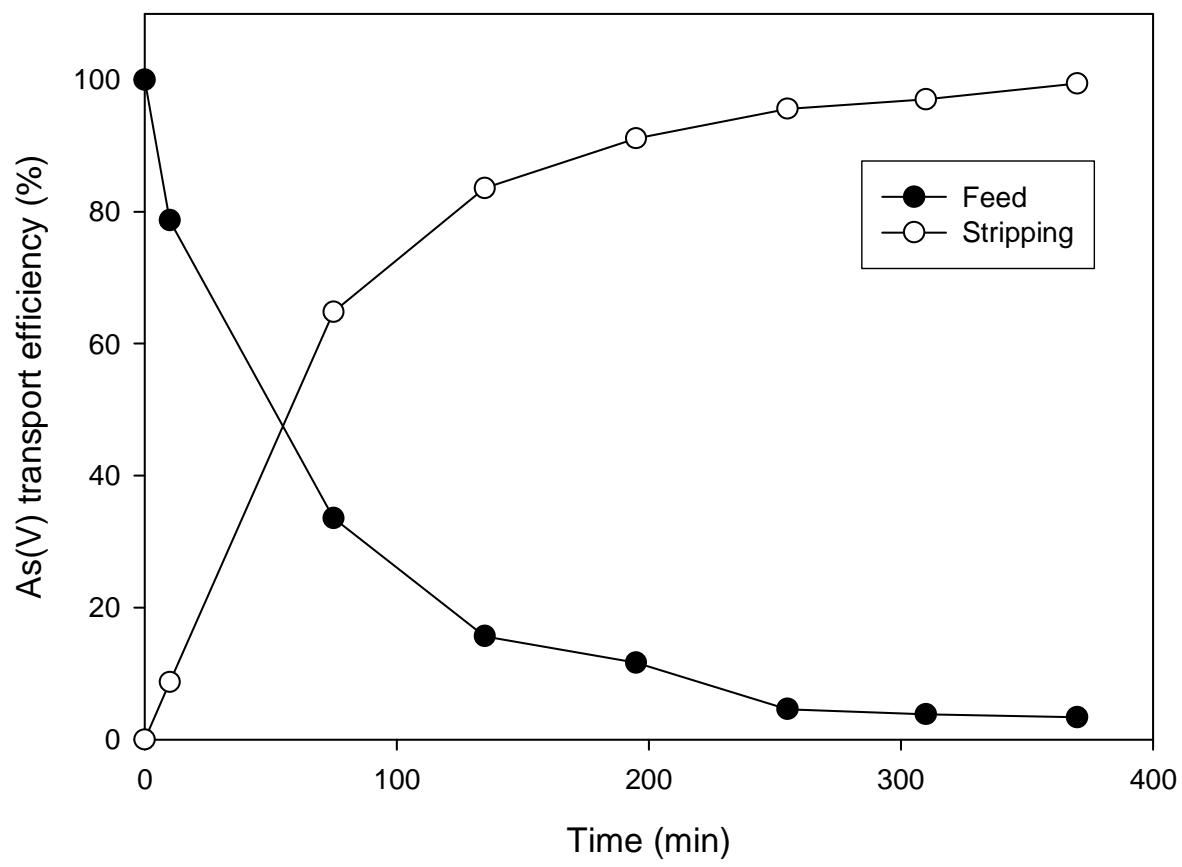


Figure 2

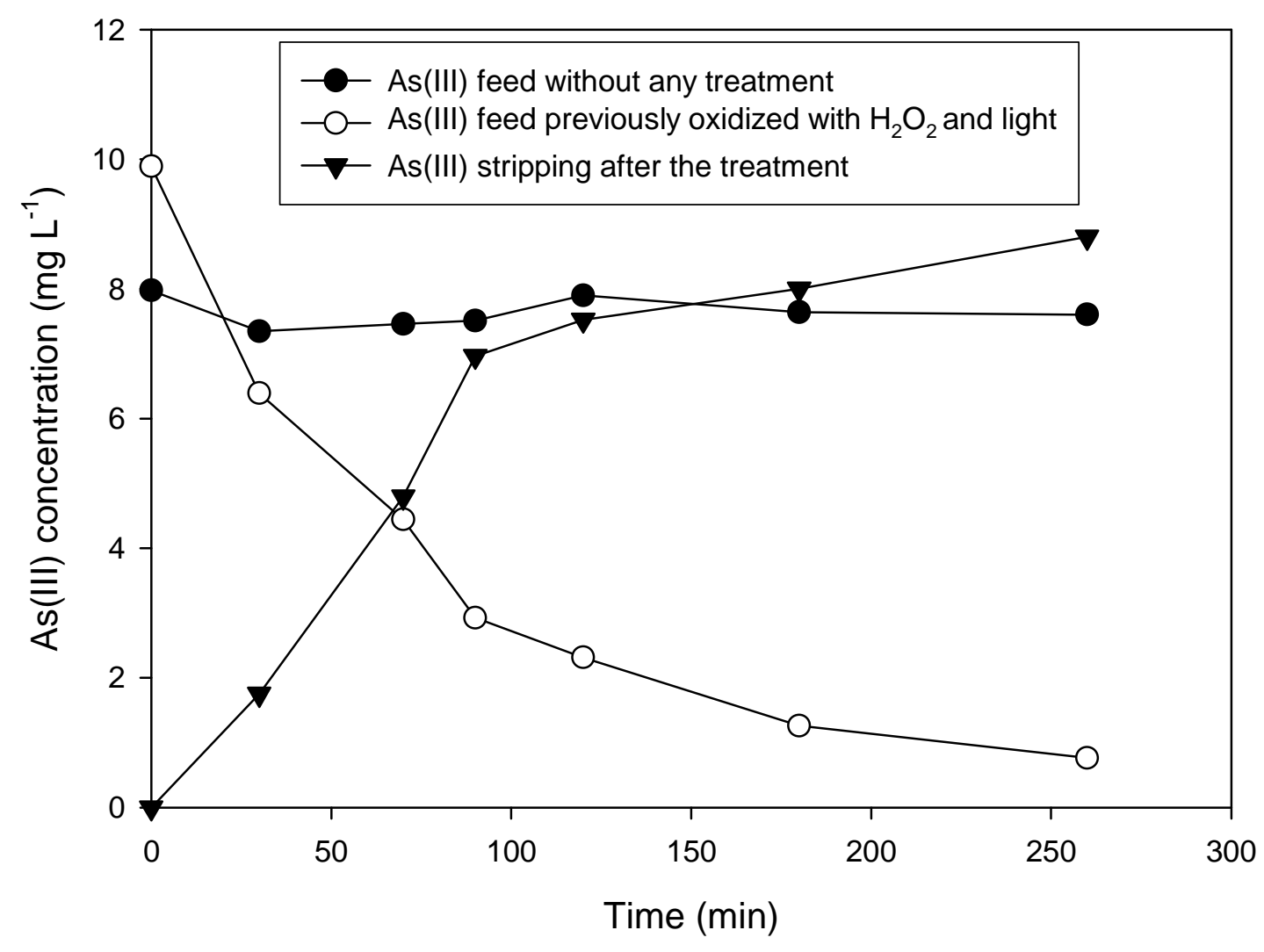


Figure 3

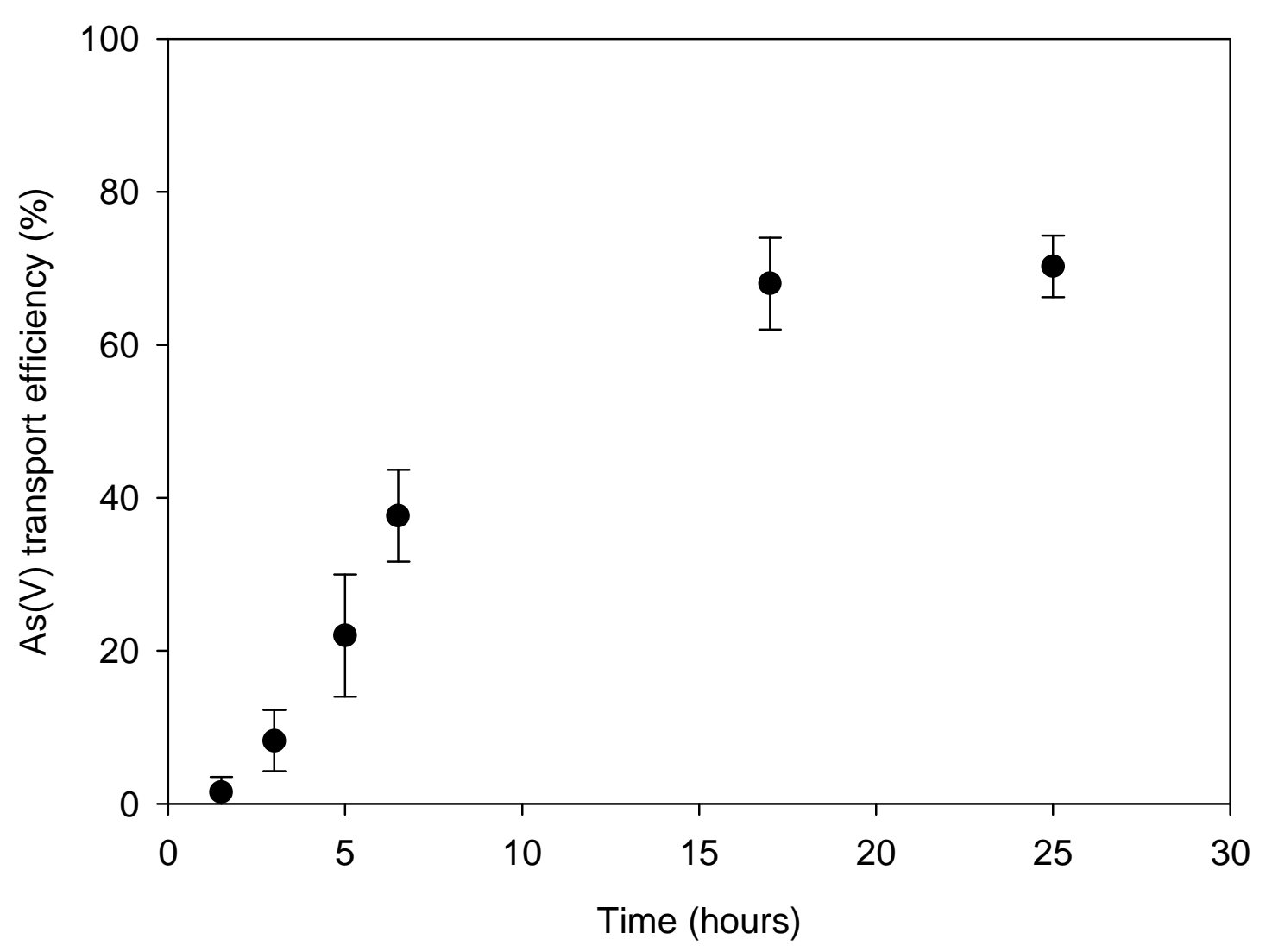


Figure 4

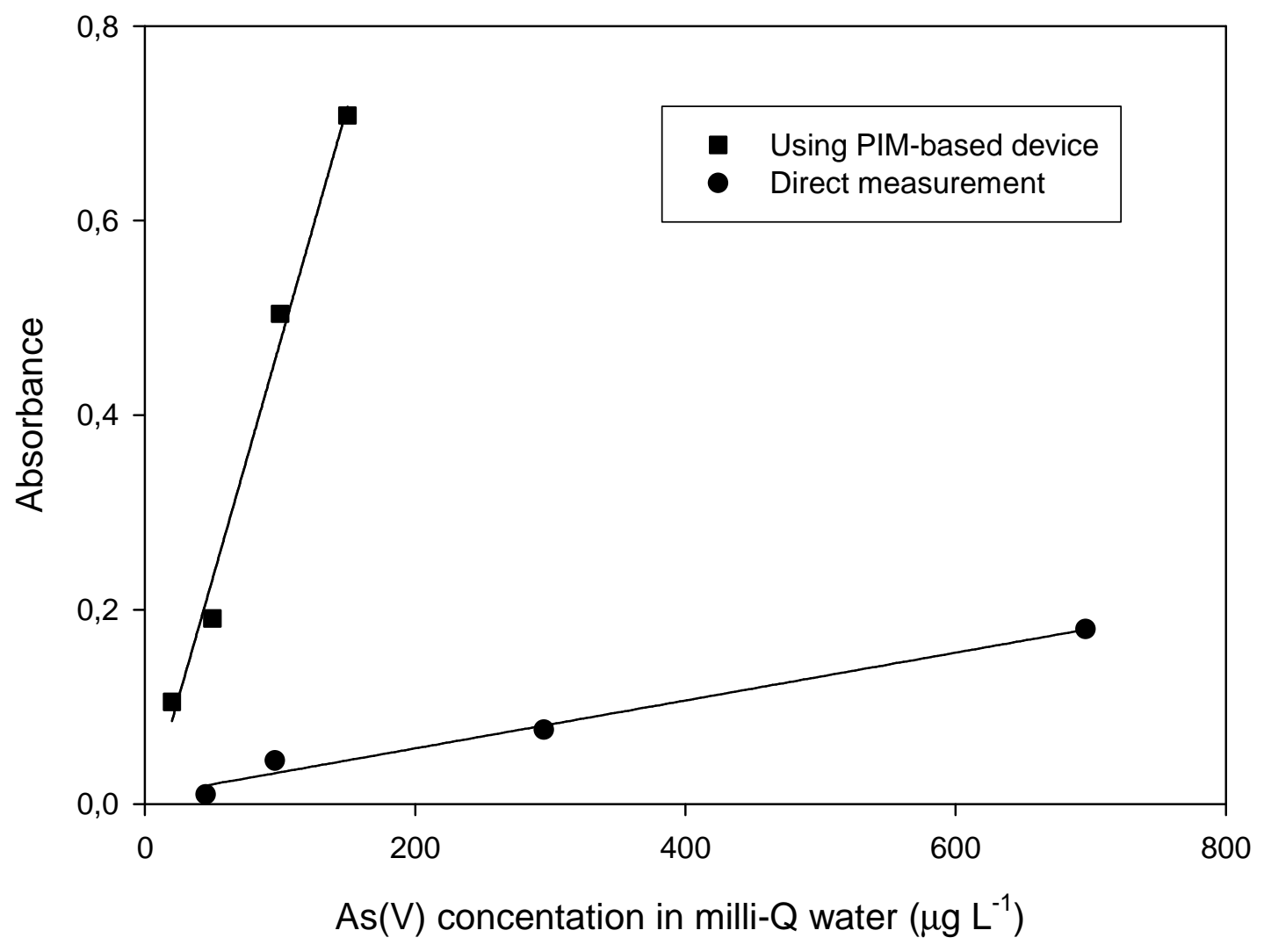


Table 1. Characteristics of the water samples used for this study. Concentrations are given in $\mathrm{mg} \mathrm{L}^{-1}$, except for As, which is in $\mu \mathrm{g} \mathrm{L}^{-1}$. Conductivity is in $\mu \mathrm{S} \mathrm{cm}^{-1}$.

Sample conductivity $\quad \begin{array}{lllllll} & \mathrm{pH} & \mathrm{Ca}^{2+} & \mathrm{Mg}^{2+} & \mathrm{Na}^{+} & \mathrm{Cl}^{-} & \mathrm{SO}_{4}{ }^{2-}\end{array}$ $\mathrm{NO}_{3}{ }^{-} \quad \mathrm{HCO}_{3}^{-} \quad \mathrm{As}\left(\mu \mathrm{g} \mathrm{L}^{-1}\right)^{*}$

\begin{tabular}{|c|c|c|c|c|c|c|c|c|}
\hline Lles 1 & 164 & & 8.60 & 10.5 & 1.1 & 38.6 & 2.8 & 13.6 \\
\hline $2.1 \quad 140$ & & 80 & & & & & & \\
\hline Lles 2 & 190 & & 8.66 & 15.3 & 2.6 & 40.1 & 2.9 & 12.4 \\
\hline $2.3 \quad 116$ & & 59 & & & & & & \\
\hline Lles 3 & 188 & & 7.26 & 23.5 & 3.7 & 32.6 & nd & nd \\
\hline nd & 160 & & 48 & & & & & \\
\hline Setcases 1 & 110 & & 7.56 & 23.6 & 2.6 & 3.7 & 0.9 & 8.0 \\
\hline $3.3 \quad 811$ & & nd & & & & & & \\
\hline Setcases 2 & 120 & & 7.55 & 27.2 & 2.5 & 3.1 & 1.0 & 15.0 \\
\hline $0.7 \quad 874$ & & 45 & & & & & & \\
\hline Setcases 3 & 94 & & 7.78 & 21.1 & 2.2 & 1.9 & 1.1 & 4.5 \\
\hline $0.8 \quad 523$ & & 2 & & & & & & \\
\hline Caldes & 3450 & & 7.14 & 33.1 & 9.0 & $>700$ & 570.0 & 41.0 \\
\hline <LOQ 2040 & & 59 & & & & & & \\
\hline Tap water & 394 & & 7.80 & 60.2 & 11.0 & 23.4 & 32.0 & 52.2 \\
\hline 182 & & 2 & & & & & & \\
\hline
\end{tabular}

nd: not detected

*Determined with ICP-MS under the conditions specified in the text. 
Table 2. Effect of water conductivity on arsenic transport efficiency of the PIM-device (described in section 2.3, $\mathrm{Vr}=20$ ). PIM: 69\% PVC-31\% Aliquat $336(\mathrm{w} / \mathrm{w})$.

\begin{tabular}{ccccc}
\hline Water sample & $\begin{array}{c}\text { Water } \\
\text { conductivity }(\boldsymbol{\mu S})\end{array}$ & $\begin{array}{c}{[\mathbf{A s}] \text { initial }} \\
\left(\boldsymbol{\mu g} \mathbf{~ L}^{-\mathbf{1}}\right)\end{array}$ & $\begin{array}{c}{[\mathbf{A s}] \text { stripping }} \\
\left(\boldsymbol{\mu} \mathbf{~ L ~}^{-\mathbf{1}}\right)\end{array}$ & $\begin{array}{c}\text { Transport } \\
\text { efficiency }(\boldsymbol{\%})\end{array}$ \\
\hline Milli-Q* & - & 100 & 1420 & 71 \\
Girona tap water* & 394 & 116 & 1750 & 75 \\
Lles 1 & 164 & 70 & 966 & 69 \\
Setcases 2 & 120 & 55 & 778 & 70 \\
Caldes & 3450 & 59 & 0 & 0 \\
\hline
\end{tabular}

* spiked samples 
Table3. Comparison of As concentration measured by ICP-MS and using the proposed method (PIM: 69\% PVC-31\% Aliquat $336(\mathrm{w} / \mathrm{w})$ ). The standard deviation is expressed in parentheses.

\begin{tabular}{ccc} 
& \multicolumn{2}{c}{ Arsenic concentration $\left(\boldsymbol{\mu} \mathbf{g ~ L}^{\mathbf{- 1}}\right)$} \\
\cline { 2 - 3 } Sample & ICP-MS $(\mathbf{n}=\mathbf{2})$ & PIM-based device $(\mathbf{n}=\mathbf{3})$ \\
\hline Lles 1 & $80(1)$ & $72(3)$ \\
Lles 2 & $59(1)$ & $63(5)$ \\
Lles 3* & 48 & 42 \\
Setcases 2 & $45(1)$ & $58(5)$ \\
Setcases 3 & $5(2)$ & $7(1)$ \\
\hline
\end{tabular}

$* \mathrm{n}=1$ 


\section{University Library}

\section{- M M N E R VA A gateway to Melbourne's research publications}

Minerva Access is the Institutional Repository of The University of Melbourne

Author/s:

Fontas, C;Vera, R;Batalla, A;Kolev, SD;Antico, E

Title:

A novel low-cost detection method for screening of arsenic in groundwater

Date:

2014-10-01

Citation:

Fontas, C., Vera, R., Batalla, A., Kolev, S. D. \& Antico, E. (2014). A novel low-cost detection method for screening of arsenic in groundwater. ENVIRONMENTAL SCIENCE AND POLLUTION RESEARCH, 21 (20), pp.11682-11688. https://doi.org/10.1007/ s11356-014-2917-5.

Persistent Link:

http://hdl.handle.net/11343/283296 